\title{
委eviews and 解ibliagraphical \%atices.
}

\section{I.-KRAFFT-EBING : HAND-BOOK OF PSYCHIATRY.}

Lharbuch der Pgychiatrik, aUf Klinischer Grundiagk, FUer PRARTIBCHE ARRZTe UND STUDIrinde. Von Dr. E. v. Krafft-Ebing, K.K.A.O. Professor der Psychiatrie an der Universitaet Graz, Director der Steiermarkischen Landesirrenanstalt, etc., etc., etc. Stuttgart : Verlag von Enke, 1879. (In three volumes.)

Meynert in his papers on the scope and methods of psychiatrical studies remarks with some sarcasm, that most of the recent hand-books published in Germany, and dealing with mental diseases, are substantially plagiarisms on Griesinger. To a great extent this is true! However much excellent work has been done by German specialists in the line of monographs and contributions to the periodical literature, it seems that the authors of systematic works have belonged to the compiling species of writers rather than to the class of original investigators and thinkers.

In the work before us we herald a new departure; it is the result of labors carried on fol many years by one of the most eminent of the new school of German alienists. It is fully up to the times, and embodies all the advances made in the field within past years. Few men are as well qualified for the task as Prof. Kraftt-Ebing, its author; for many years the medical director of one of the best Austrian asylums, a teacher of clinical psychiatry in one of the universities, and the leader among German medical jurisconsults, be is enabled to grasp the subject of Insanity from different points of view, and to deal with it in a manner satisfactory to the many classes of readers who are apt to seek for information in a text-book on Insanity.

While the practical issues are thus dealt with in an almost unexceptionably able manner, we regret to note that the anatomical and physiological remarks exhibit a haziness of conception and an imperfection in detail that we are painfully surprised at. We can only wish that Prof. Krafft-Ebing had either omitted this portion from his work altogether, or else, like Leidesdorf, entrusted the writing of it to some one who had mastered the subject. We will return to this matter at the close of the review, for although a subsidiary one, yet it is but proper that the short-comings even in the less practical fields should be pointed out.

Of the three volumes comprising the work, the first deals with the general pathology and therapeutics of Insanity, the second 
great value of the work as a whole. It is a monument of patience, diligence and skifl; it is eminently practical, and its perusal cannot fail to profit every worker in the field of nervous and mental diseases, who will turn to it of course not to obtain information in anatomy and physiology, but in the diagnosis and treatment of the most mysterious affections of the nervous system.

In how high esteem our author holds the accessory sciences, and how thoroughly he is imbued with the idea that insanity is but a branch of general neuro-pathology, let the concluding lines of his second introductory chapter attest:

"From all these facts follows the practically important dictum, that all the methods of observation and treatment of the socalled diseases of the mind must be the same as those applied to other cerebral diseases, and that only he can intelligently recognize and treat them who has the various diagnostic aids at his disposal, and possesses special knowledge of the physiology and pathology of the entire nervous system."

E. C. SPITZKA.

II.-DOWSE : NEURALGIA: ITS NATURE AND CURATIVE TREATMENT.

Neuralgia : Its Nature and Curative Treatment. (The Brain and Diseases of the Nervous System, vol. II.) By 'Thomas Stretch Dowse, M. D. G. P. Putnam's Sons, 182 Fif th Avenue. New York, 1880. Pages, 198.

In his preface the author says: "If the reader expects to find in the following pages any vague or speculative theories relative to the pathology of neuralgia, he will be greatly mistaken."

This statement will be found true, for the book does not contain a theory of neuralgia of any kind worthy of the name. If the author regards theories or rational explanations of important groups of morbid phenomena, such as are observed in neuralgias, us impossible or useless, or necessarily "vague or speculative," he is sadly in error. If, however, he means to be understood as simply declining for the present to offer a theory or explanation of the phenomena of neuralgia, then he should be permitted quietly to have his own way. But, in any case, it seems stlange a writer should either lay so little stress upon having and giving a sensible theory, or should allow himself so little time and space as to reuder such a course impractioable when he sets himself down deliberately to write a book on such a subject. For our own part we do not lesitate to condemn, whether in medical practice or medical writings, the irrational haste to get at "prac. tical" results whicl so often involves the neglect of thoughtful rational theory. If we may be permitted to judge from what 